\title{
Numerical Simulation of the Topographical Change in Korea Mountain Area by Intense Rainfall and Consequential Debris Flow
}

\author{
Byong-Hee Jun \\ Department of Disaster Prevention \& Safety Engineering, Kangwon National University, Samcheok 245-905, Republic of Korea \\ Correspondence should be addressed to Byong-Hee Jun; bhjun@kangwon.ac.kr
}

Received 20 April 2015; Revised 16 July 2015; Accepted 12 August 2015

Academic Editor: Zhongping Lai

Copyright (C) 2016 Byong-Hee Jun. This is an open access article distributed under the Creative Commons Attribution License, which permits unrestricted use, distribution, and reproduction in any medium, provided the original work is properly cited.

The objectives of this study are to simulate the topographical changes associated with rainfall and the consequential debris flow using terrestrial LiDAR (Light Detection And Ranging). Three rainfall events between July 9 and July 14, 2009, triggered a number of debris flows at Jecheon County in Korea. Rain fell at a rate of $64 \mathrm{~mm} / \mathrm{h}$, producing $400 \mathrm{~mm}$ of total accumulation during this period. Tank simulation model for SWI (Soil Water Index) estimated the water stored beneath the ground and debris flow occurrence in study area. For the LiDAR (Light Detection and Ranging) survey, the terrestrial laser scanning system RIEGL LMS-Z390i consists of an accurate and fast 3D scanner, associated RTK GPS system. The DEM derived from LiDAR enabled the debris flow to be mapped and analyzed in great detail. The estimated affected area and erosion/deposition volumes by debris flow were compared with two-dimensional numerical simulation. The simulation results were sufficiently in good agreement with the debris flow track, and a success rate of over $90 \%$ was achieved with a simulation time of $300 \mathrm{~s}$. A comparison of the simulated and surveyed results based on deposition volume yields a success rate of over $97 \%$ with $350 \mathrm{~s}$ of simulation time.

\section{Introduction}

Since the debris flows generally transport huge volumes of sediments in mountain torrents, it is important to understand the characteristics of erosion, transportation, and deposition of debris flows, especially mountainous areas. In a previous study, the peak discharge of the water and sediment mixture was reported to be an order of magnitude greater, and the density of the mixture can be two times greater than the density of water [1]. Moreover, the debris flow discharges are much higher than clean water discharges; thus, the hydrodynamic forces are increased [2]. Climatic factors are an important subject for a better understanding of hydrological response of landslide activity and are essential for developing landslide/debris flow warning systems. Intense rainstorms may directly trigger shallow landslides $(<3 \mathrm{~m}$ deep), and an upper threshold for landslide initiation with rainfall intensity and rainfall duration was defined. The Indian Ocean monsoon produces seasonal precipitation in Korea [3], which causes landslides and debris flows. Recently, these events have resulted in notably higher damage [4]. In both Korea and all around Northeast Asia, the sediments in debris flows often cause catastrophic damage in local communities [5].

Many researchers have proposed mathematical models of debris flow. A number of these models employ empirical formulas concerning run-out and deposition [6-9]. Other models focus on the physical and dynamic aspects of debris flows [10-14]. In recent studies, incorporating numerical simulations with GIS (Geographic Information System) enabled the evaluation of debris flow risk through the integrated simulation of triggering, propagation, and deposition [15, 16]. Takahashi [10] used Bagnold's dilatants fluid hypothesis and proposed that the erosion/deposition rate is a function of sediment concentration and controlled by the excess concentration over the equilibrium concentration. These models incorporate the rheological properties, such as friction parameters, as input data, and back calculation is usually required for estimating these rheological properties.

The observation of topographic changes with highresolution imaging can help validate debris flow simulations. 
LiDAR (Light Detection and Ranging) is a remote sensing technology that collects three-dimensional point clouds of the surface. LiDAR data has already been used for studying landslide morphology and distribution [17-19], local relief $[20,21]$, channel bed morphology $[22,23]$, and headwater channel network analysis [24, 25], as well as for the hill slope-to-valley transition [26]. LiDAR data also enables the calculation of surface characteristics [27] and the extraction of geometry and identification of failure [28]. Various researchers have investigated the effect of DEM (Digital Elevation Model) resolution on landscape representation [2931]. These data were combined with landslide observations and landslide models [32]. The benefits of laser scanning are the ability to quickly generate data of an object surface, easy leveling process, and fewer human errors [33].

This study presents results from quantification of the volume and pattern of debris flow deposits using DEMs generated from GPS (Global Positioning System) measurement through the LiDAR survey. The objectives of this study are to identify the morphological changes associated with the debris flow and to determine the affected area and total volume of debris flow using high-resolution terrestrial LiDAR. The estimated results of the affected area and erosion/deposition volumes by debris flow were compared with the numerical simulation results.

\section{Methods}

2.1. Study Area. Due to an intensive rainfall from 9 to 14 July 2009 in Jecheon County, a large number of debris flows occurred around the mountainous area. The study examined one of these debris flow occurrences areas in Jecheon County, which is located at $37^{\circ} 07^{\prime} \mathrm{N}$ latitude and $128^{\circ} 04^{\prime} \mathrm{E}$ longitude. Figure 1 shows the location and morphology of study area and also shows channelized debris flow. The damage from these debris flows was large; they destroyed 2 houses on the apex and 6 houses at the alluvial fan and damaged several vinyl greenhouses and all of the fields around the channels. The morphologies of the basin and channel in this study are listed in Table 1 . The area of catchment is approximately $1.22 \mathrm{~km}^{2}$, rising from $275 \mathrm{~m}$ to $680 \mathrm{~m}$, with water flowing NW.

Figure 2 shows an aerial photograph of the study area and a terrestrial photograph of areas with erosion or deposition. The white circles (A), (B), and (C) represent the area of the subsequent photograph. The rectangular transparent gray zone represents the LiDAR scanning area for this study, which is also applied to the mathematical simulation.

Figure 3 shows the rainfall events at Baekun weather station near the study area from 7 to 16 July 2009. In Jecheon County, six weather stations were operated, and, among them, the Baekun weather station was closest to the study area. The rainfall data indicates that high intensive and sequential rainfall occurred between July 9 and July 14, totaling $455.5 \mathrm{~mm}$. Rainfall intensity increased on July 14 to the maximum rainfall intensity of $64 \mathrm{~mm} / \mathrm{h}$ and $201 \mathrm{~mm} / \mathrm{d}$ at Baekun weather station and debris flow occurred at 21:00 on July 14.

High water content is necessary for soil saturation, and it was reported that most debris flows occurred during or after
TABLE 1: Topographic parameters in study area.

\begin{tabular}{lc}
\hline Parameters (unit) & Value \\
\hline Basin area $\left(\mathrm{km}^{2}\right)$ & 1.22 \\
Basin maximum elevation (m, a.s.l.) & 680 \\
Basin minimum elevation (m, a.s.l.) & 275 \\
Basin mean elevation (m, a.s.l.) & 464 \\
Basin mean slope (degree) & 22.0 \\
Channel length (m) & 2,030 \\
Channel slope (degree) & 7.8 \\
Debris flow area slope (degree) & 11.9 \\
\hline
\end{tabular}

heavy and sustained rainfalls [34]. Antecedent moisture also plays an important role in the saturation of soils, and it rises with groundwater level and soil moisture $[35,36]$. The SWI (Soil Water Index) has been used as a variable in landslide and debris flow warning systems [37]. SWI estimates the water stored beneath the ground and landslide disaster occurrence by comparing current and past SWI values. Tank simulation models for SWI evaluation are semiphysical models that generalize the geometrical, spatial, and material conditions. Due to the simplicity, a tank model can be used for long time periods and GIS applications [38]. This model also shows how long it takes for rain to become groundwater. We verified the SWI in this study area and investigated the applicability of a tank model. In this study, SWI was defined to be the total storage thickness of the three tanks.

Figure 4 shows the part of temporal variation from 1 to 31 July 2009 in the study area. Three major rainfall events occurred within six days and the sequence of debris flow events in the study area started on 14 July 2009 during the third rainfall peak, which had a maximum rainfall intensity of $64 \mathrm{~mm} / \mathrm{h}$ and $201 \mathrm{~mm} / \mathrm{d}$. The temporal variations of SWI represent the possibility of prediction tools for landslide occurrence. The antecedent rainfall seemed to have a strong effect on triggering debris flows in this study area.

2.2. LiDAR Scanning. For the LiDAR survey, the terrestrial laser scanning system RIEGL LMS-Z390i consists of a highly accurate and fast 3D scanner using TOF (time of flight) method, associated RTK GPS system, and high-resolution digital camera. The TOF method calculates the time taken by the light pulse and finds $x, y$, and $z$ coordinates and the distance from the source to the object. TOF scanner used in this study has the ability to measure 11,000 points every second. The point cloud contains information including $x, y$, and $z$ coordinates.

The LiDAR provides high-resolution DEMs that provide better land surface representation. In debris flow studies, LiDAR is often used in conjunction with other datasets such as DEMs derived from photogrammetry to compare with LiDAR topography. To gather and compare the digital information available for the study area, we used ArcGIS tools, which enabled volume calculations.

2.3. Numerical Model. A mathematical model is applied to simulate the debris flow in study area. The fundamental theory of the numerical model is based on mass and 


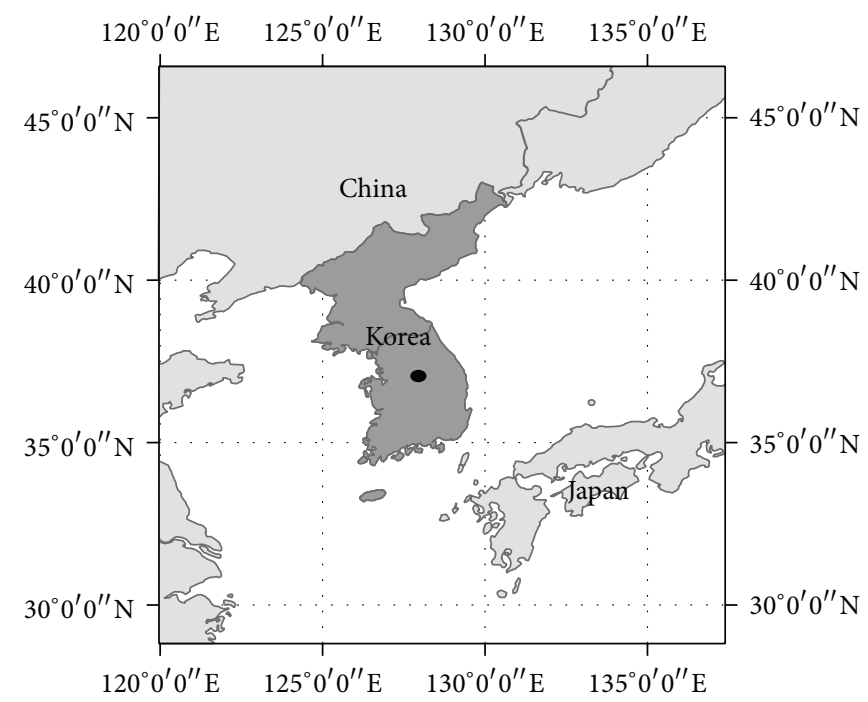

(a)

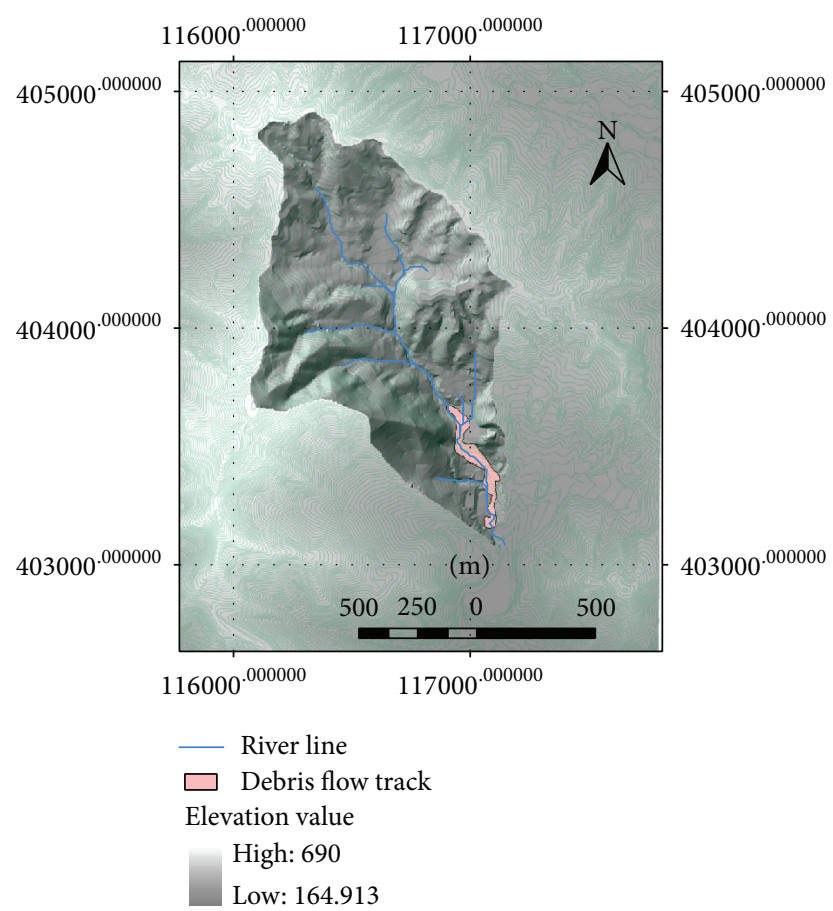

(b)

Figure 1: The location of study area (a) and debris flow occurring in basin (b).

momentum conservation with a shallow-water assumption and storm-induced debris flow often moves as a continuous fluid until stoppage [39]. To estimate the debris flow, this study adopted Takahashi model [10], which treats a debris flow as a steady fully developed laminar flow and assumes that the flow is dilatants fluid and governed by Navier-Stokes and continuity equations. The model fluid is considered a solidliquid mixture of sediments and interstitial fluid. Assuming that the solids and the interstitial fluid move downstream with the same velocity, the flow of the mixture is described using a two-dimensional depth averaged model with a $2 \mathrm{D}$ momentum equation and two mass balance equations for the mixture and the sediments. Differential equations are integrated with an upwind explicit finite-difference scheme. By introducing shear stresses at the flow surface, the depthwise averaged two-dimensional momentum equations of debris flow for $x$ (down valley) and $y$ (lateral) directions are described as follows:

$$
\begin{aligned}
& \frac{\partial M}{\partial t}+\beta \frac{\partial(u M)}{\partial x}+\beta \frac{\partial(v M)}{\partial y} \\
& \quad=g h \sin \theta_{b x 0}-g h \cos \theta_{b x 0} \frac{\partial\left(z_{b}+h\right)}{\partial x}-\frac{\tau_{b x}}{\rho_{T}}, \\
& \frac{\partial N}{\partial t}+\beta \frac{\partial(u N)}{\partial x}+\beta \frac{\partial(v N)}{\partial y} \\
& =g h \sin \theta_{b y 0}-g h \cos \theta_{b y 0} \frac{\partial\left(z_{b}+h\right)}{\partial y}-\frac{\tau_{b y}}{\rho_{T}},
\end{aligned}
$$

where $M(=u h)$ and $N(=v h)$ are the flow discharge per unit width in $x$ and $y$ directions, $t$ is time, $u$ and $v$ are the velocity components in $x$ and $y$ directions, $\beta$ is momentum correction factor equal to 1.25 for a stony debris flow, $g$ is gravitational acceleration, $h$ is flow depth, $\theta_{b x 0}$ and $\theta_{b y 0}$ are $x$ and $y$ components of the slope of the original bed surface, $z_{b}$ is erosion or deposition thickness of the bed measured from the original bed surface elevation, $\tau_{b x}$ and $\tau_{b y}$ are the bottom shear stresses in $x$ and $y$ directions, and $\rho_{T}$ is the mixture density.

The continuity equation of the total volume is

$$
\frac{\partial h}{\partial t}+\frac{\partial M}{\partial x}+\frac{\partial N}{\partial y}=i_{b}
$$

where $i_{b}$ is the erosion $(\geq 0)$ or deposition $(<0)$ velocity.

The continuity equation of the coarse particle fraction that is sustained in the flow by the action of particle encounters is

$$
\frac{\partial(C h)}{\partial t}+\frac{\partial(C M)}{\partial x}+\frac{\partial(C N)}{\partial y}=i_{b} C_{*}
$$

where $C$ is the volumetric sediment concentration in the flow and $C_{*}$ is the volumetric sediment concentration in the original bed. The erosion or deposition thickness to calculate the bed surface elevation is given by

$$
\frac{\partial z_{b}}{\partial t}+i_{b}=0
$$

The change of the debris flow density can be modeled through the mass balance of both phases (solid and liquid) and the 

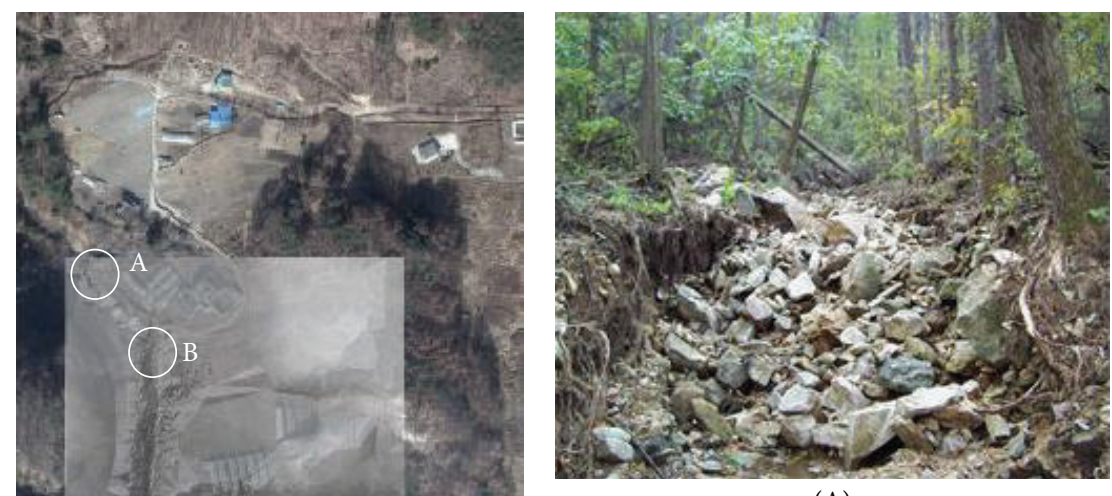

(A)

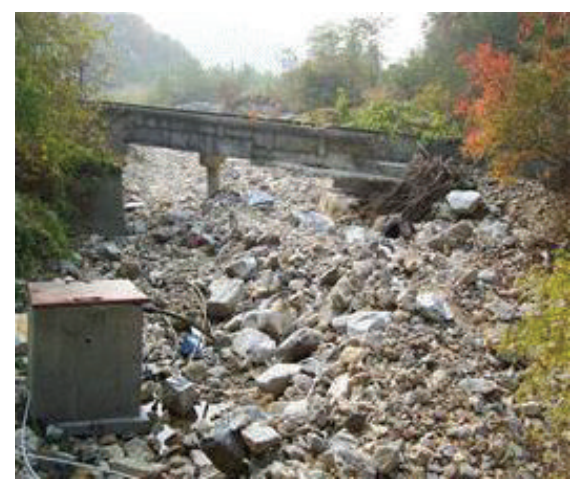

(B)

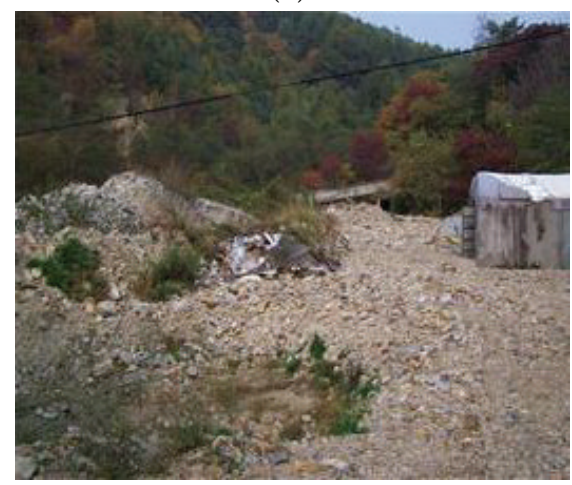

(C)

FIGURE 2: The aerial photograph in study area and terrestrial photograph showing flooding area.

definition of the erosion/deposition rate as a function of the sediments concentration. The debris flow can be numerically simulated by two-dimensional governing equations composed of the momentum conservation equation for the mixture of solid and liquid, the mass conservation equations for the liquid phase and solid phase, respectively, and the equation for bed height change. Since the resistance term involves the momentum conservation equations, the different constitutive equations for fully developed stony debris flow and immature debris flow and turbulent flow should be contained in the momentum conservation equation. The bottom resistance for a two-dimensional flow is described as follows.
For a fully developed stony debris flow $\left(C>0.4 C_{*}\right)$,

$$
\begin{aligned}
& \tau_{b x}=\frac{u}{\sqrt{u^{2}+v^{2}}} \tau_{y x}+\rho f_{b} u \sqrt{u^{2}+v^{2}}, \\
& \tau_{b y}=\frac{v}{\sqrt{u^{2}+v^{2}}} \tau_{y y}+\rho f_{b} v \sqrt{u^{2}+v^{2}},
\end{aligned}
$$

in which $\tau_{y x}$ and $\tau_{y y}$ are the yield stresses in $x$ and $y$ directions, which can be expressed using constitutive equations of Takahashi et al. [40]. 


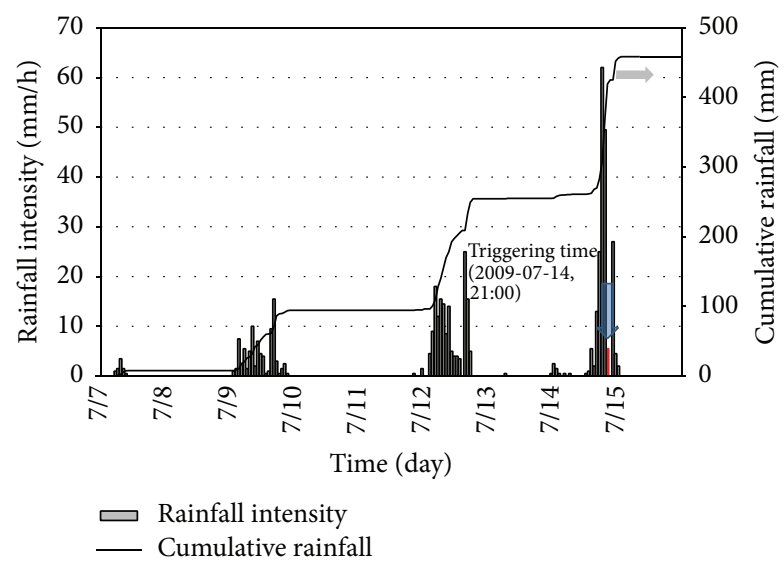

FIGURE 3: Rainfall at Baekun weather station on 7-16 July 2009.

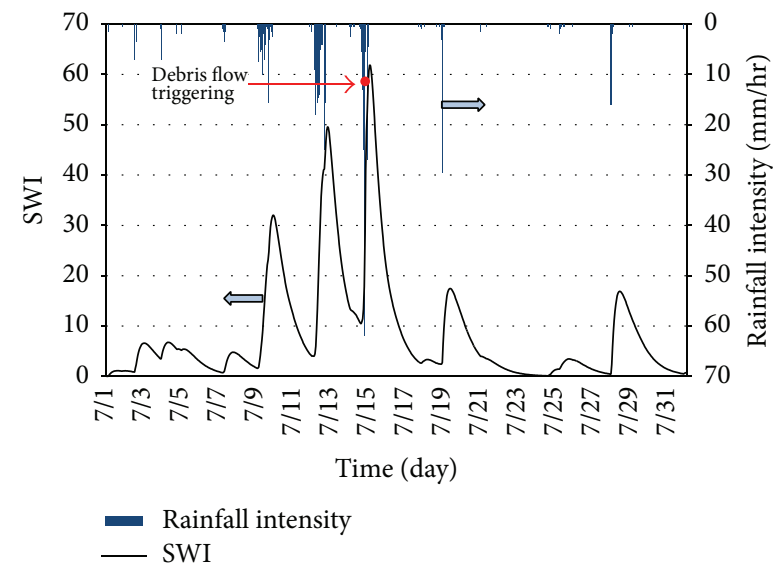

FIgURE 4: Temporal variation in Soil Water Index from 1 to 31 July 2009 in Jecheon area.

For an immature debris flow $\left(0.02 \leq C \leq 0.4 C_{*}\right)$,

$$
\begin{aligned}
& \tau_{b x}=\frac{\rho_{T}}{0.49}\left(\frac{d_{m}}{h}\right)^{2} u \sqrt{u^{2}+v^{2}} \\
& \tau_{b y}=\frac{\rho_{T}}{0.49}\left(\frac{d_{m}}{h}\right)^{2} v \sqrt{u^{2}+v^{2}}
\end{aligned}
$$

For a turbulent flow $(C<0.02)$,

$$
\begin{aligned}
& \tau_{b x}=\frac{\rho g n^{2} u \sqrt{u^{2}+v^{2}}}{h^{1 / 3}}, \\
& \tau_{b y}=\frac{\rho g n^{2} v \sqrt{u^{2}+v^{2}}}{h^{1 / 3}} .
\end{aligned}
$$

Since the volume of debris flow traveling downstream will increase with the bed erosion or decrease with deposition, the erosion and deposition velocity equations should be contained in the mass conservation equations. The erosion and deposition velocity equations for two-dimensional debris flow model are given by Takahashi et al. [40].
TABLE 2: Summary of values used in simulations.

\begin{tabular}{lc}
\hline Parameters (unit) & Value \\
\hline Solid density $\left(\mathrm{kg} / \mathrm{m}^{3}\right)$ & 2.65 \\
Fluid density $\left(\mathrm{kg} / \mathrm{m}^{3}\right)$ & 1 \\
Volumetric sediment concentration in bed & 0.65 \\
Mean diameter of sediment particle $(\mathrm{m})$ & 0.03 \\
Gravity acceleration $\left(\mathrm{m} / \mathrm{s}^{2}\right)$ & 9.8 \\
Erosion coefficient & 0.0007 \\
Deposition coefficient & 0.05 \\
Tangent of internal friction angle of sediment & 0.7 \\
Manning coefficient & 0.04 \\
Time interval $(\mathrm{s})$ & 0.02 \\
Mesh size $(\mathrm{m})$ & 5 \\
\hline
\end{tabular}

Erosion velocity equation is

$$
i_{b}=\delta_{e} \frac{C_{\infty}-C}{C_{*}-C_{\infty}} \frac{\sqrt{u^{2}+v^{2}} h}{d_{m}},
$$

where $\delta_{e}$ is erosion coefficient and $C_{\infty}$ is the equilibrium concentration.

Deposition velocity equation for a fully developed stony debris flow is

$$
i_{b}=\delta_{d}\left(1-\frac{\sqrt{u^{2}+v^{2}}}{p U_{e}}\right) \frac{C_{\infty}-C}{C_{*}} \sqrt{u^{2}+v^{2}},
$$

where $\delta_{d}$ is deposition coefficient, $p(=2 / 3)$ is numerical constant, and $U_{e}$ is the equilibrium velocity at which neither erosion nor deposition takes place as follows:

$$
\begin{aligned}
U_{e}= & \frac{2}{5 d_{m}}\left[\frac{g \sin \theta_{e}}{a_{i} \sin \alpha_{i}}\left\{C+(1-C) \frac{\rho_{m}}{\sigma}\right\}\right]^{1 / 2} \\
& \cdot\left\{\left(\frac{C_{*}}{C}\right)^{1 / 3}-1\right\} h^{3 / 2},
\end{aligned}
$$

where $\theta_{e}$ is channel slope in which sediment concentration is in equilibrium, which can be obtained as follows:

$$
\tan \theta_{e}=\frac{C\left(\sigma-\rho_{m}\right) \tan \phi}{C\left(\sigma-\rho_{m}\right)+\rho_{m}} .
$$

For the cases of an immature debris flow and a turbulent flow, the respective deposition equation is expressed as

$$
i_{b}=\delta_{d} \frac{C_{\infty}-C}{C_{*}} \sqrt{u^{2}+v^{2}}
$$

The input values and unit of the parameters for simulations are listed in Table 2.

Taking into consideration a previous study by Salciarini et al. [41], the soil depth was assumed to be $3 \mathrm{~m}$, based on the results from terrestrial LiDAR survey. A simulation time interval of $0.01 \mathrm{~s}$ was used for the simulation of debris flow. 


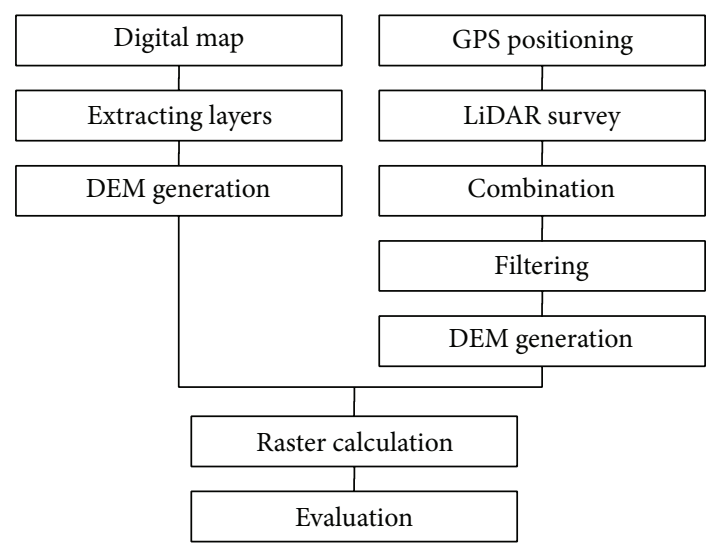

FIgURE 5: Main LiDAR processing steps in this study.

\section{Result and Discussion}

3.1. LiDAR Scanning. Figure 5 shows the DEM manipulation and the main LiDAR processing steps in a flow chart. For the DEM generation before the debris flow, we used a digital map that was provided by Korea Geography Information Institute because there was no available LiDAR data around study area. The digital map with 1:5000 scale was constructed in 2007, and the DEM before the occurrence was generated with the grid cell of $5 \mathrm{~m} \times 5 \mathrm{~m}$ spatial resolution.

The first step in LiDAR survey involves the RTK GPS (Global Position System) receiver setup. The LiDAR survey produces quantification of the volume and pattern of debris flow deposits using DEM generated from GPS and LiDAR data [42]. Synchronization of GPS and LiDAR was obtained using the starting point as a reference for the survey processes. The GPS and LiDAR sensor were both connected to a computer for the data management and storage. The LiDAR scanning integrated the georeferenced cloud points. The study area required scanning from 21 locations to capture debris flow track geometry and these 21 locations were combined to one dataset. Due to the presence of vegetation and houses, mask and filtering was performed.

Next, a triangulated irregular network (TIN) was constructed for the point cloud. Finally, a raster DEM was generated with $5 \mathrm{~m} \times 5 \mathrm{~m}$ spatial resolution. The DEM generation was performed using the universal Kriging interpolation method. Using these two DEMs, further raster calculations were performed by ArcGIS. A number of results can be derived from the raw data, including morphology, geometry, and cross-sectional profiles.

Figure 6 shows the capture of whole cloud points combined by the RiSCAN PRO program, which is the companion software for RIGLE terrestrial 3D laser scanner system along the debris flow track. The study area consisted of 21 scanning points to capture whole debris flow track. Initial raw data consisting of more than 350,000 points required postprocessing before DEM generation. The first step in postprocessing involves the elimination of points identified as beyond the nominal ground surface. Next, the objects except the surface of the earth should be removed from the original data by

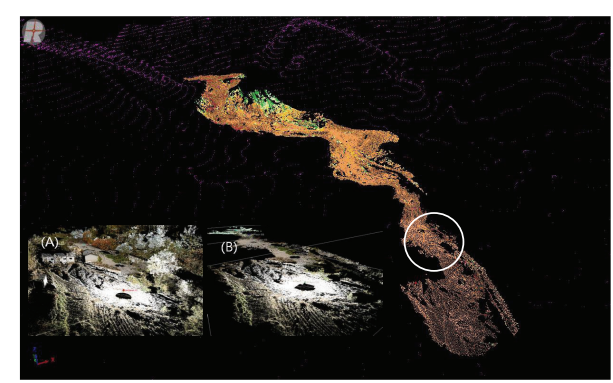

FIGURE 6: The capture of combined cloud points: original LiDAR range image subjected to debris flow (A) and cutting result of forest canopies and artificial structures (B).

filtering. The points returned from forest around the debris flow track are identified and removed using visual inspection of the 3D data. Figure 6(A) shows a magnified part (white circle) of original scanning point cloud data including some woods and artificial structures and Figure 6(B) shows the filtered point cloud data at the same area with (A).

Figure 7 shows the topographic map before (a) or after (b) debris flow. The left upper corner of the figure shows the area upstream of the debris flow track. Figure 7(b) shows the highresolution DEM as a result of overlapping the digital map and 3D point cloud data. Figure 7(b) also shows obvious erosion scars in the upstream region and detailed topography features all over debris flow track. It is shown that the debris flow track tends to reach a configuration of dynamic equilibrium in the downstream zone, while in the upstream zone the erosion is dominant.

Through the raster calculation of results in Figure 7, we can calculate erosion and deposition. Figure 8 shows the evaluated values of erosion and deposition depth. The blue and brown areas represent erosion and deposition areas, respectively. Whereas deep erosion was shown at the upstream region, the erosion became smaller and the deposition more broad downstream. Figure 8 also represents the affected area of the debris flow track. Furthermore, the volume changes by the debris flow event could be estimated based on a comparison between the eroded or deposited surface area and its heights. Next, the total volume and area of erosion and of deposition were calculated by summing the negative and positive pixels, respectively. According to this comparison, the erosion volume was approximately $32,847 \mathrm{~m}^{3}$ and the deposition volume was approximately $22,889 \mathrm{~m}^{3}$, respectively. As a consequence, it was thought that discharged sediment volume was $9,958 \mathrm{~m}^{3}$. Generally, a debris volume could increase during the landslide event, as a consequence of the deposition during the landslide [18]. However, the deposition volume was estimated to be less than that of erosion. The underestimated deposition volume can be assumed to be discharge volume into the reservoir located downstream of the study area.

The debris flow volumes and discharges can be much greater than clean water due to rainfall. The density of the mixture is two times greater than that of the liquid flow. In 


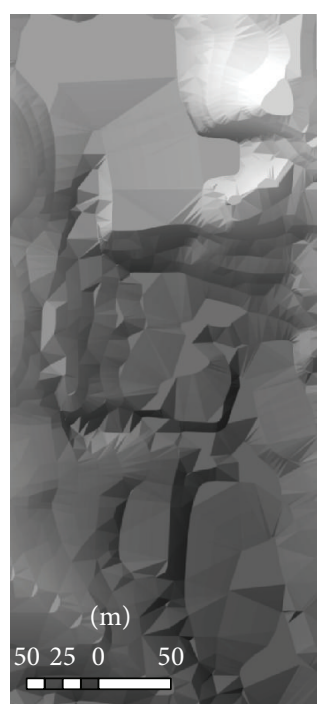

(a)

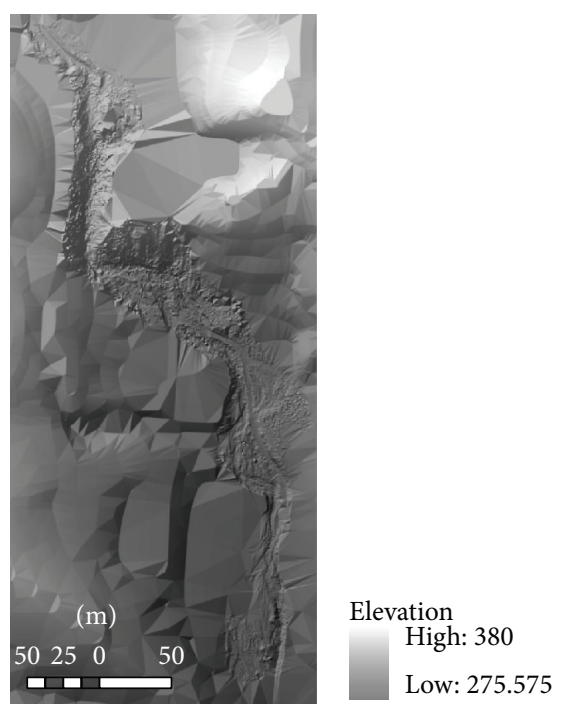

(b)

FIgURE 7: Topographic map before (a) and after (b) debris flow.

consequence, the hydrodynamic forces acting on the structure are increased. Therefore, the debris flow volumes should be considered to design hydraulic structures such as dams and bridges. With the classification of Jakob [2], the flow was rated as size class 4 , which could destroy parts of village and destroy sections of infrastructure corridors and bridges.

3.2. Topographical Change Simulation. A debris flow model is used to simulate the transport and deposition of failed materials from the identified source areas. In absence of any recorded discharge amount on the upper part of triggering point, a rectangular discharge hydrograph with flow of $20 \mathrm{~m}^{3} / \mathrm{s}$ was assumed. The computational domain was discrete with $108 \times 48$ square cells with a size of $5 \mathrm{~m}$. A DEM was obtained from a 1:5000 digital map and was not refined anywhere. Figure 9 shows the morphological variations evaluated between the initial condition and the temporal progression of the simulated debris flows. The solid line represents the affected area results from the LiDAR survey as shown in Figure 8.

In Takahashi model, if debris flow contains lower solid concentration than the equilibrium concentration, the bed would be eroded, and if the solid concentration is higher than the equilibrium value, solid would be deposited. This method was applied to cases of laboratory experiment [43] and various field researches [4]. Comparing with stochastic method such as random walk model deciding the flow direction by the probability proportional to the flow velocities calculated from the elevation differences between the adjacent grid points, demerit of random walk model is that the deposition proceeds with one-dimensional motion despite the complex topology [44]. This study uses horizontally two-dimensional momentum conservation and mass conservation equations representing the two-dimensional flow.

It reveals that the simulation results are sufficiently good excluding the northern part of the domain where the model

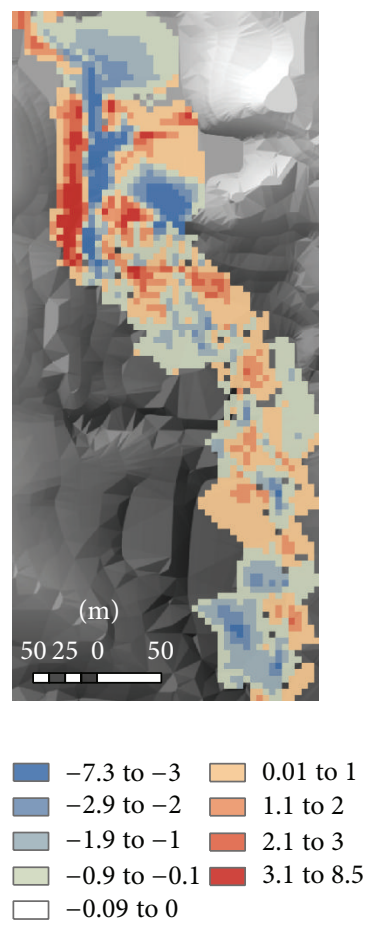

FIGURE 8: The evaluated values of erosion and deposition depth.

simulates wide spreading of the wave in the upper stream. This broad deposition did not occur in the real world event. Debris flow moves with the mean velocity of $3.5 \mathrm{~m} / \mathrm{s}$ along a path with the average slope of $11.9^{\circ}$.

To validate the model performance, we extracted the affected area with a terrestrial LiDAR survey and compared the affected area with the results of debris flow simulation. Figure 10 shows the details of the model performance in predicting the affected areas. 

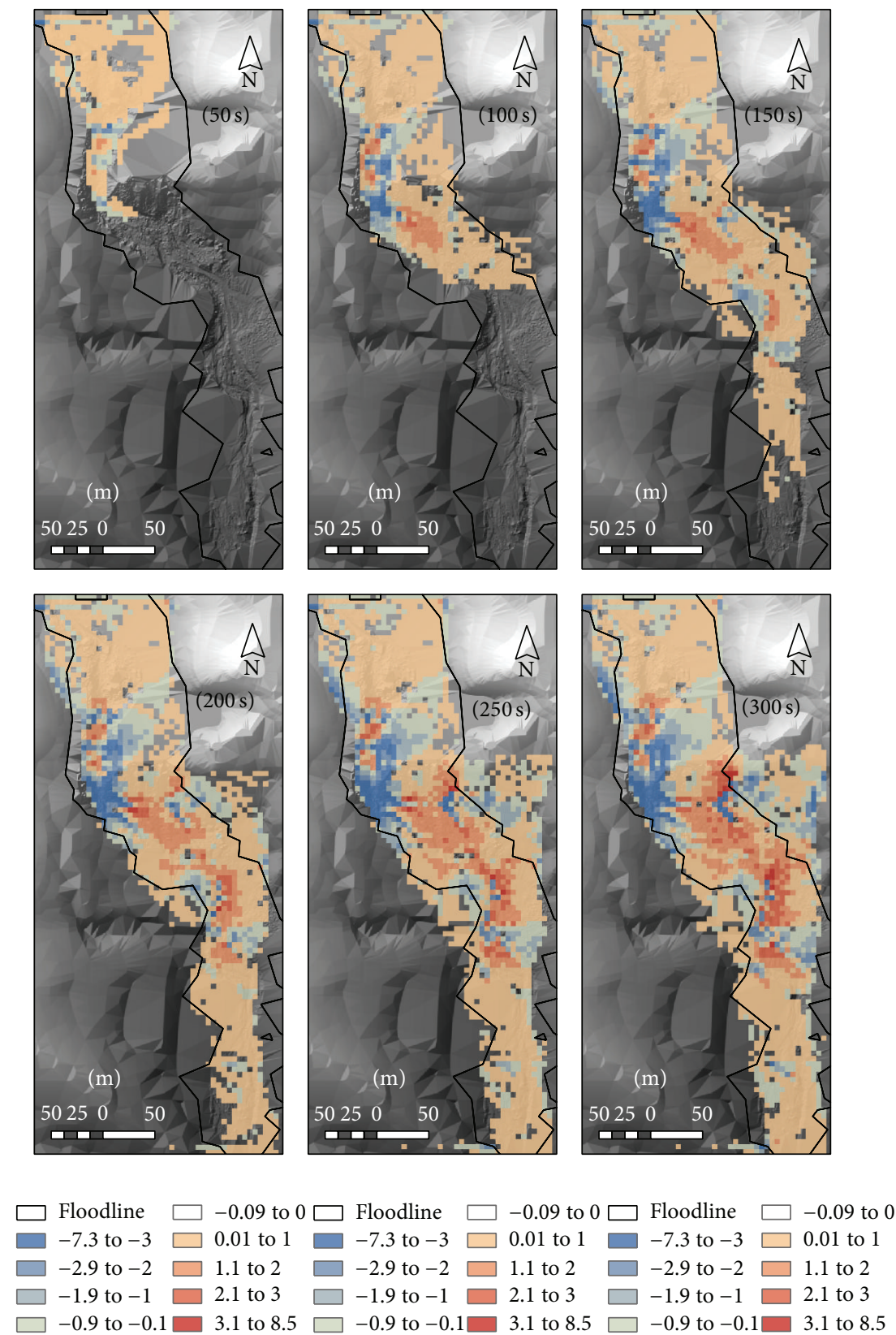

FIGURE 9: The temporal progression of the simulated debris flows.

For the evaluation of success rate, the proportions of successfully predicted affected areas $\left(A_{s}\right)$ were calculated:

$$
A_{s}=\frac{N_{p}}{N_{t}} \times 100(\%),
$$

where $N_{t}$ is the total cell number of surveyed affected areas and $N_{p}$ is the correctly simulated cell number within the affected areas. In Figure 9, the solid line represents the terrestrial LiDAR surveyed affected areas and corresponds to $N_{t}$. The differences between the solid line area and colored area by the simulation time represent the discordances with the surveyed area and the simulated results. A high success rate over $90 \%$ was achieved with a simulation time of $300 \mathrm{~s}$.

Moreover, because the terrestrial LiDAR survey results have depth information, we could validate simulated erosion/deposition volume change along within the affected area. The depth of sediment deposition before and after debris flow can be used to estimate the model performance [45]. The second validation defined the prediction accuracy by calculating the ratio of the simulated erosion/deposition volume and surveyed erosion/deposition volume, respectively.

Figure 11 shows the simulated erosion/deposition volume and the success rate. In this study, deposition volumes were lower than erosion volumes. For the success rate evaluation of 


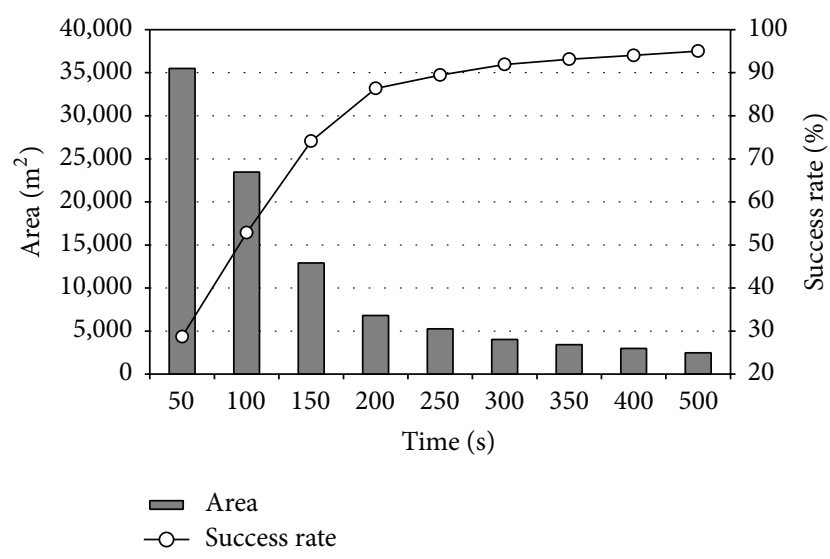

FIGURE 10: Variation of discordance area and the success rate.

the erosion/deposition volume, the proportions of predicted erosion/deposition volume and measured erosion/deposition volume by the LiDAR survey $\left(V_{s}\right)$ were calculated:

$$
V_{s}=\frac{V_{\text {simulated }}}{V_{\text {measured }}} \times 100(\%),
$$

where $V_{\text {measured }}$ is the LiDAR surveyed erosion/deposition volume as shown in Figure 8 and $V_{\text {simulated }}$ is the simulated erosion/deposition volume. A comparison of the simulated and survey results, based on the deposition volume, yields a success rate of over $97 \%$ at $350 \mathrm{~s}$ simulation time. The erosion volume success rate reaches the highest value at $500 \mathrm{~s} \mathrm{simu-}$ lation time. It was thought that this delayed result is probably due to the soil depth limitation in the model assumptions.

The results reproduced both the zone affected by the debris flow and the spatial distribution of sediments with reasonable accuracy for most of the domain. The model test and validation results confirm the usefulness of the model in calculating the number and size of affected areas, run-out path, and volume of run-out deposits.

These results suggest some important considerations for technicians dealing with the protection of the mountain areas from intense rainfall. This debris flow model can be applied to design and construct the hydraulic structures like dams and bridges with the consideration of hydraulic forces. The hydraulic structures have been designed referring to the peak discharge and the volume was regarded to be of minor importance. However, the numerical model can show the propagation and the stoppage of the debris flow by the hydraulic structure. The simulation and validation results confirm the usefulness of the model for creating hazard maps and reducing debris flow risk.

\section{Conclusions}

This study presented the tank simulation model for SWI estimating the water stored beneath the ground and debris flow occurrence using high-resolution terrestrial LiDAR at the Jecheon County in Korea. The DEM derived from the LiDAR enabled the debris flow to be mapped and analyzed

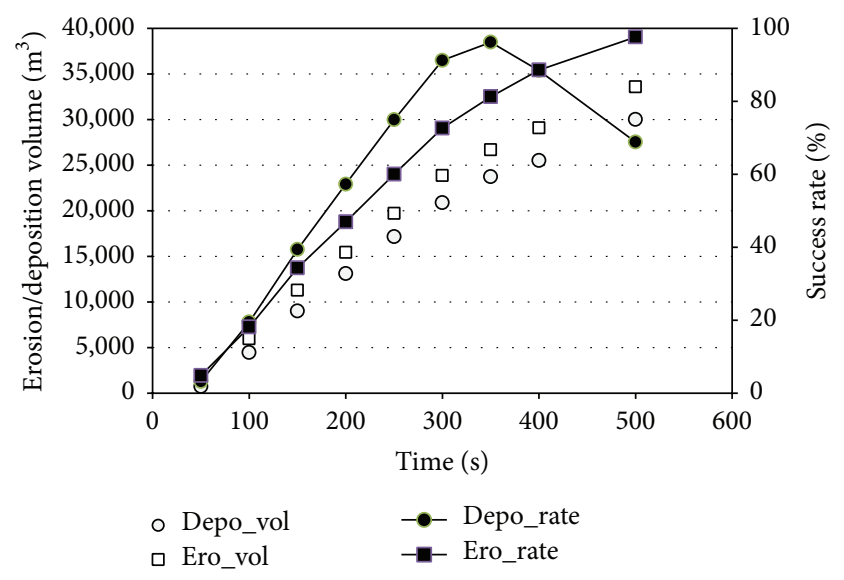

FIGURE 11: Variation of erosion/deposition volume and its success rate.

in great detail. The study area required scanning from 21 locations to capture debris flow track geometry and these 21 locations were combined to one dataset. The morphological change associated with the debris flow and the affected area and total erosion/deposition volume by debris flow were calculated. The estimated volumes of erosion and deposition are $32,847 \mathrm{~m}^{3}$ and $22,889 \mathrm{~m}^{3}$, respectively. The estimated results of affected area and erosion/deposition volume by debris flow were compared with two-dimensional numerical simulation results. We adopted Takahashi model for the friction terms, which treats a debris flow as a dilatant fluid and is governed by Navier-Stokes and continuity equations. The simulation results agreed well with the debris flow track, and a high success rate of over $90 \%$ was achieved with simulation time of $300 \mathrm{~s}$. A comparison of the simulated and surveyed results based on the deposition volume yields a success rate of over $97 \%$ at $350 \mathrm{~s}$ simulation time. The erosion volume success rate reaches the highest value at $500 \mathrm{~s}$ simulation time. It was thought that this delayed result is probably due to the soil depth limitation in the model assumptions. These results revealed both the area affected by the debris flow and the spatial distribution of sediments with reasonable accuracy for most of the study area. The simulation and validation results confirm the usefulness of the model for creating hazard maps and reducing debris flow risk. These results suggest some important considerations for technicians dealing with the protection of the mountain areas from intense rainfall.

\section{Conflict of Interests}

The author declares that there is no conflict of interests regarding the publication of this paper.

\section{Acknowledgment}

This research was supported by a grant ("Development of Multi-Function Debris Flow Control Technique Considering Extreme Rainfall Event") [MPSS-NH-2014-74] from the National Hazard Mitigation Research Group, Ministry of Public Safety and Security of Korea. 


\section{References}

[1] P. Ghilardi, L. Natale, and F. Savi, "Modeling debris flow propagation and deposition," Physics and Chemistry of the Earth Part C: Solar, Terrestrial \& Planetary Science, vol. 26, no. 9, pp. 651-656, 2001.

[2] M. Jakob, "A size classification for debris flows," Engineering Geology, vol. 79, no. 3-4, pp. 151-161, 2005.

[3] D. Kim, S. Im, S. H. Lee, Y. Hong, and K.-S. Cha, "Predicting the rainfall-triggered landslides in a forested mountain region using TRIGRS model," Journal of Mountain Science, vol. 7, no. 1, pp. 83-91, 2010.

[4] D. W. Park, N. V. Nikhil, and S. R. Lee, "Landslide and debris flow susceptibility zonation using TRIGRS for the 2011 Seoul landslide event," Natural Hazards and Earth System Sciences, vol. 13, no. 11, pp. 2833-2849, 2013.

[5] T. Mizuyama, "Structural countermeasures for debris flow disasters," International Journal of Erosion Control Engineering, vol. 1, no. 2, pp. 38-43, 2008.

[6] M. Berti and A. Simoni, "Prediction of debris flow inundation areas using empirical mobility relationships," Geomorphology, vol. 90, no. 1-2, pp. 144-161, 2007.

[7] M. Hürlimann, D. Rickenmann, V. Medina, and A. Bateman, "Evaluation of approaches to calculate debris-flow parameters for hazard assessment," Engineering Geology, vol. 102, no. 3-4, pp. 152-163, 2008.

[8] M. Portilla, G. Chevalier, and M. Hürlimann, "Description and analysis of the debris flows occurred during 2008 in the Eastern Pyrenees," Natural Hazards and Earth System Science, vol. 10, no. 7, pp. 1635-1645, 2010.

[9] C. S. Magirl, P. G. Griffiths, and R. H. Webb, "Analyzing debris flows with the statistically calibrated empirical model LAHARZ in southeastern Arizona, USA," Geomorphology, vol. 119, no. 1-2, pp. 111-124, 2010.

[10] T. Takahashi, Debris Flow, Balkema, Rotterdam, The Netherlands, 1991.

[11] B. Hunt, "Newtonian fluid mechanics treatment of debris flows and avalanches," Journal of Hydraulic Engineering, vol. 120, no. 12, pp. 1350-1363, 1994.

[12] R. M. Iverson, M. E. Reid, and R. G. LaHusen, "Debris-flow mobilization from landslides," Annual Review of Earth and Planetary Sciences, vol. 25, pp. 85-138, 1997.

[13] H. M. Blijenberg, "Application of physical modelling of debris flow triggering to field conditions: limitations posed by boundary conditions," Engineering Geology, vol. 91, no. 1, pp. 25-33, 2007.

[14] Z. Han, G. Chen, Y. Li et al., "Numerical simulation of debrisflow behavior incorporating a dynamic method for estimating the entrainment," Engineering Geology, vol. 190, pp. 52-64, 2015.

[15] B. Q. Luna, A. Remaître, T. W. J. van Asch, J.-P. Malet, and C. J. van Westen, "Analysis of debris flow behavior with a one dimensional run-out model incorporating entrainment," Engineering Geology, vol. 128, pp. 63-75, 2012.

[16] G. T. Aronica, G. Biondi, G. Brigandì, E. Cascone, S. Lanza, and G. Randazzo, "Assessment and mapping of debris-flow risk in a small catchment in eastern Sicily through integrated numerical simulations and GIS," Physics and Chemistry of the Earth Parts A/B/C, vol. 49, pp. 52-63, 2012.

[17] J. McKean and J. Roering, "Objective landslide detection and surface morphology mapping using high-resolution airborne laser altimetry," Geomorphology, vol. 57, no. 3-4, pp. 331-351, 2004.
[18] R.-F. Chen, K.-J. Chang, J. Angelier et al., “Topographical changes revealed by high-resolution airborne LiDAR data: the 1999 Tsaoling landslide induced by the Chi-Chi earthquake," Engineering Geology, vol. 88, no. 3-4, pp. 160-172, 2006.

[19] J. Iwahashi, I. Kamiya, and H. Yamagishi, "High-resolution DEMs in the study of rainfall- and earthquake-induced landslides: use of a variable window size method in digital terrain analysis," Geomorphology, vol. 153-154, pp. 29-38, 2012.

[20] G. Priestnall, J. Jaafar, and A. Duncan, "Extracting urban features from LiDAR digital surface models," Computers, Environment and Urban Systems, vol. 24, no. 2, pp. 65-78, 2000.

[21] H. X. Volker, T. A. Wasklewicz, and M. A. Ellis, "A topographic fingerprint to distinguish alluvial fan formative processes," Geomorphology, vol. 88, no. 1-2, pp. 34-45, 2007.

[22] M. Cavalli, P. Tarolli, L. Marchi, and G. D. Fontana, "The effectiveness of airborne LiDAR data in the recognition of channelbed morphology," Catena, vol. 73, no. 3, pp. 249-260, 2008.

[23] G. Ventura and G. Vilardo, "Emplacement mechanism of gravity flows inferred from high resolution Lidar data: the 1944 Somma-Vesuvius lava flow (Italy)," Geomorphology, vol. 95, no. 3-4, pp. 223-235, 2008.

[24] S. A. White and Y. Wang, "Utilizing DEMs derived from LIDAR data to analyze morphologic change in the North Carolina coastline," Remote Sensing of Environment, vol. 85, no. 1, pp. 3947, 2003.

[25] A. Vianello, M. Cavalli, and P. Tarolli, "LiDAR-derived slopes for headwater channel network analysis," Catena, vol. 76, no. 2, pp. 97-106, 2009.

[26] P. Tarolli and G. D. Fontana, "Hillslope-to-valley transition morphology: new opportunities from high resolution DTMs," Geomorphology, vol. 113, no. 1-2, pp. 47-56, 2009.

[27] N. F. Glenn, D. R. Streutker, D. J. Chadwick, G. D. Thackray, and S. J. Dorsch, "Analysis of LiDAR-derived topographic information for characterizing and differentiating landslide morphology and activity," Geomorphology, vol. 73, no. 1-2, pp. 131-148, 2006.

[28] S. A. Dunning, C. I. Massey, and N. J. Rosser, "Structural and geomorphological features of landslides in the Bhutan Himalaya derived from Terrestrial Laser Scanning," Geomorphology, vol. 103, no. 1, pp. 17-29, 2009.

[29] W. Zhang and D. R. Montgomery, "Digital elevation model grid size, landscape representation, and hydrologic simulations," Water Resources Research, vol. 30, no. 4, pp. 1019-1028, 1994.

[30] L. Claessens, G. B. M. Heuvelink, J. M. Schoorl, and A. Veldkamp, "DEM resolution effects on shallow landslide hazard and soil redistribution modelling," Earth Surface Processes and Landforms, vol. 30, no. 4, pp. 461-477, 2005.

[31] P. Tarolli and D. G. Tarboton, "A new method for determination of most likely landslide initiation points and the evaluation of digital terrain model scale in terrain stability mapping," Hydrology and Earth System Sciences, vol. 10, no. 5, pp. 663-677, 2006.

[32] H. Hu, T. M. Fernandez-Steeger, M. Dong, and R. Azzam, "Numerical modeling of LiDAR-based geological model for landslide analysis," Automation in Construction, vol. 24, pp. 184193, 2012.

[33] J.-C. Du and H.-C. Teng, "3D laser scanning and GPS technology for landslide earthwork volume estimation," Automation in Construction, vol. 16, no. 5, pp. 657-663, 2007.

[34] J.-P. Malet, D. Laigle, A. Remaître, and O. Maquaire, "Triggering conditions and mobility of debris flows associated to complex earthflows," Geomorphology, vol. 66, pp. 215-235, 2005. 
[35] E. J. Gabet, D. W. Burbank, J. K. Putkonen, B. A. PrattSitaula, and T. Ojha, "Rainfall thresholds for landsliding in the Himalayas of Nepal," Geomorphology, vol. 63, no. 3-4, pp. 131143, 2004.

[36] R. K. Dahal and S. Hasegawa, "Representative rainfall thresholds for landslides in the Nepal Himalaya," Geomorphology, vol. 100, no. 3-4, pp. 429-443, 2008.

[37] K. Sassa, H. Fukuoka, F. Wang, G. Wang, K. Okada, and H. Marui, "Landslide disasters triggered by the 2004 mid-niigata prefecture earthquake in Japan," Annuals of Disaster Prevention Research Institute, vol. 49, pp. 119-136, 2006.

[38] D. Brunsden, "Some geomorphological considerations for the future development of landslide models," Geomorphology, vol. 30, no. 1-2, pp. 13-24, 1999.

[39] C. Wang, T. Esaki, M. Xie, and C. Qiu, "Landslide and debrisflow hazard analysis and prediction using GIS in MinamataHougawachi area, Japan," Environmental Geology, vol. 51, no. 1, pp. 91-102, 2006.

[40] T. Takahashi, H. Nakagawa, T. Harada, and Y. Yamashiki, "Routing debris flows with particle segregation," Journal of Hydraulic Engineering, vol. 118, no. 11, pp. 1490-1507, 1992.

[41] D. Salciarini, J. W. Godt, W. Z. Savage, R. L. Baum, and P. Conversini, "Modeling landslide recurrence in Seattle, Washington, USA," Engineering Geology, vol. 102, no. 3-4, pp. 227-237, 2008.

[42] S. J. Conway, A. Decaulne, M. R. Balme, J. B. Murray, and M. C. Towner, "A new approach to estimating hazard posed by debris flows in the Westfjords of Iceland," Geomorphology, vol. 114, no. 4, pp. 556-572, 2010.

[43] P. Brufau, P. García-Navarro, P. Ghilardi, L. Natale, and F. Savi, "1D mathematical modelling of debris flow," Journal of Hydraulic Research, vol. 38, no. 6, pp. 435-446, 2000.

[44] T. Takahashi, "A review of Japanese debris flow research," International Journal of Erosion Control Engineering, vol. 2, no. 1, pp. 1-14, 2009.

[45] M.-H. Li, R.-T. Sung, J.-J. Dong, C.-T. Lee, and C.-C. Chen, "The formation and breaching of a short-lived landslide dam at Hsiaolin Village, Taiwan-part II: simulation of debris flow with landslide dam breach," Engineering Geology, vol. 123, no. 1-2, pp. 60-71, 2011. 

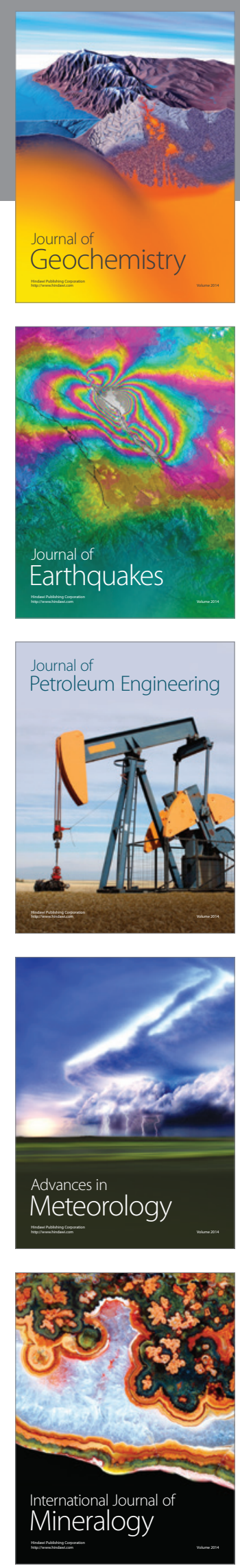
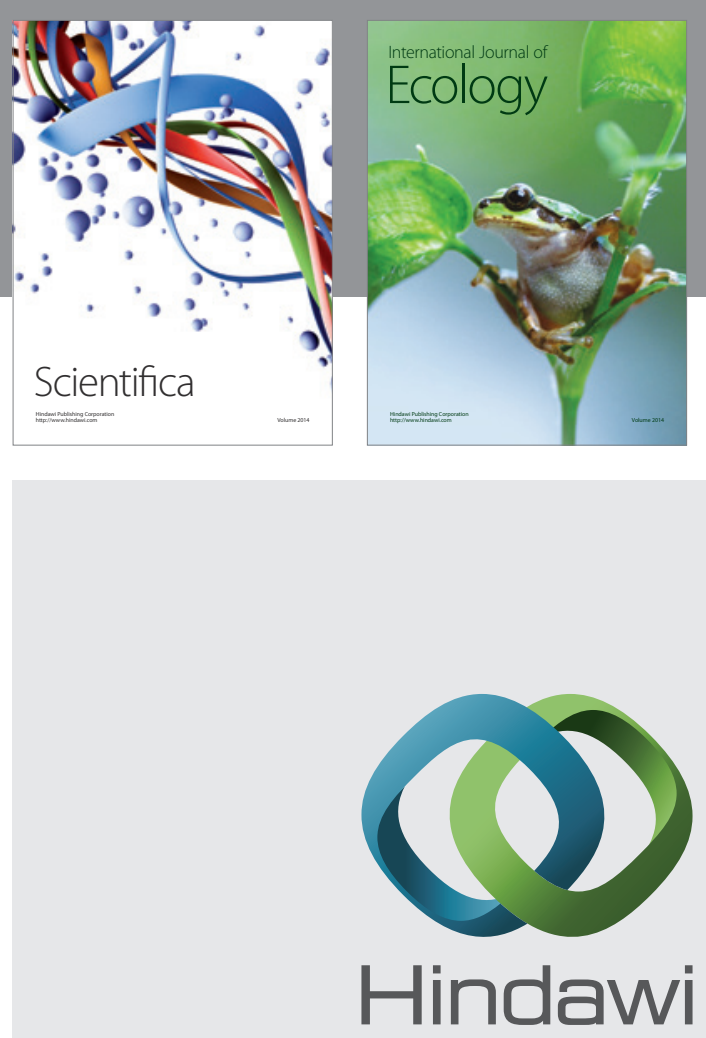

Submit your manuscripts at

http://www.hindawi.com
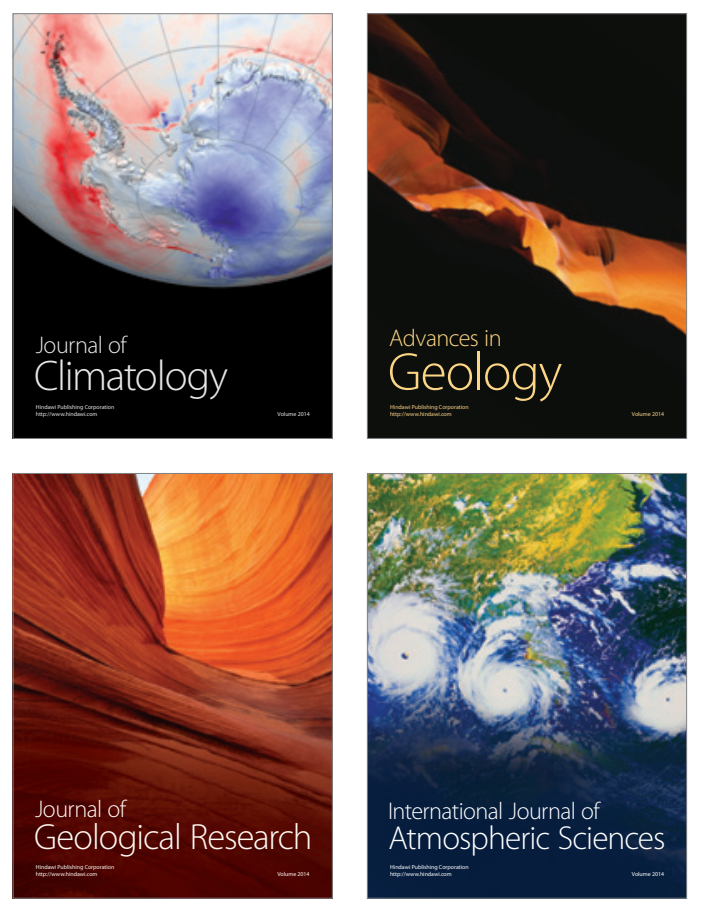

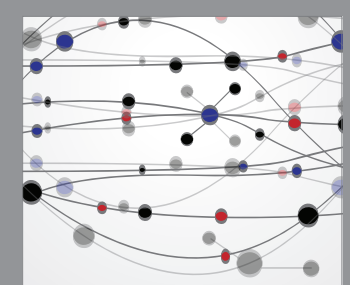

The Scientific

\section{World Journal}
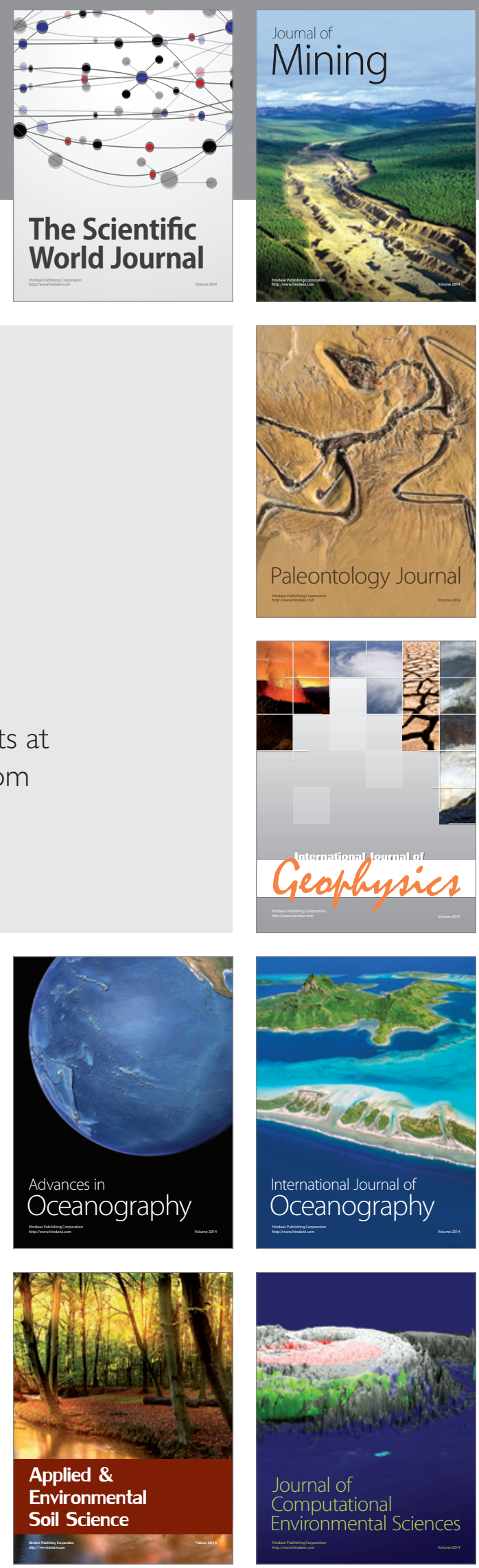